\title{
A viagem de perséfone: o diálogo entre a mitologia grega e o conceito de estações do ano
}

The journey of perséfone: the dialogue between the greek mithology and the concept of seasons

El viaje de perséfone: el diálogo entre la mitología griega y el concepto de estaciones del año

Letícia Aparecida Ferreira de Abreu Licencianda - Ciências Biológicas, UFLA, Brasil. Ifabreu5@gmail.com

Augusto Antonio de Paula Licenciando - Ciências Biológicas, UFLA, Brasil. augustodiipaula@gmail.com

\section{José Alberto Casto Nogales Vera}

Professor Doutor, UFLA, Brasil. jnogales@dfi.ufla.br

Antonio Fernandes Nascimento Junior Professor Doutor, UFLA, Brasil. toni_nascimento@yahoo.com.br 
RESUMO

O presente trabalho apresenta e discute uma experiência realizada no âmbito da disciplina de Metodologia do Ensino de Ciências do curso de licenciatura em Ciências Biológicas da Universidade Federal de Lavras - MG, (UFLA), a fim de entender como a utilização da mitologia grega contribui para a construção do conceito de Estações do Ano. Além disso, o trabalho, também, tem o intuito de verificar como a disciplina auxilia a formação inicial de professores. Para a realização da análise deste trabalho foi utilizada a pesquisa qualitativa. E dentro da pesquisa qualitativa, foi utilizado o método de análise por categorias, derivado da análise de conteúdo. A análise foi feita em cima de relatos escritos e discutida com o referencial adotado. Ainda, o trabalho busca contribuir para discussões acerca do contexto em que o ensino de ciências está inserido. A partir das discussões trazidas, foi possível notar a importância do uso do Mito na construção de conhecimentos e, para além disso, perceber a relevância da disciplina na formação docente.

PALAVRAS-CHAVE: Formação de professores. Ensino de ciências. Mitologia grega na educação.

\section{ABSTRACT}

The present work presents and discusses an experiment carried out in the discipline of Methodology of the Teaching of Sciences of the undergraduate course in Biological Sciences of the Federal University of Lavras - MG (UFLA), in order to understand how the utilization of Greek mythology contributes to the construction of the concept of Seasons of the year. In addition, this work, also, aims to verify how this discipline helps the initial training of teachers. For the analysis of this work, qualitative research was used. In the qualitative research the method of analysis by categories, derived from the analysis of content was used. The analysis was carried out on the written and discussed stories within the theoretical framework adopted. The paper seeks to contribute to discussions about the context in which the teaching of science is embedded. From the analysis of the discussion it was possible to notice the importance of the use of the myth in the construction of knowledge and, in addition, to perceive the relevance of the discipline in the Teacher training.

KEYWORDS: Teacher training. Teaching of Sciences. Greek mythology in education.

\section{RESUMEN}

El presente trabajo presenta y discute una experiencia realizada en el ámbito de la disciplina de Metodología de la Enseñanza de Ciencias del curso de licenciatura en Ciencias Biológicas de la Universidad Federal de Lavras - MG (UFLA), a fin de entender cómo la utilización de la mitología griega contribuye para la construcción del concepto de Estaciones del año. Además, este trabajo, también, tiene el propósito de verificar cómo esta disciplina ayuda a la formación inicial de profesores. Para la realización del análisis de este trabajo, se utilizó la investigación cualitativa. En la investigación cualitativa se utilizó el método de análisis por categorías, derivado del análisis de contenido. El análisis se lo realizo sobre los relatos escritos y discutidos dentro del marco teórico adoptado. El trabajo busca contribuir a discusiones acerca del contexto en que la enseñanza de las ciencias está inserta. A partir del análisis de la discusión fue posible notar la importancia del uso del Mito en la construcción de conocimientos y, además, percibir la relevancia de la disciplina en la Formación docente.

PALABRAS-CLAVE: Formación de profesores; Enseñanza de las ciências; Mitología griega en la educación. 


\section{INTRODUÇÃO}

O ensino fundamental representa um dos níveis da educação básica e, segundo os Parâmetros Curriculares Nacionais (Brasil, 1998), tem como um dos objetivos auxiliar o educando em seu posicionamento crítico, responsável e construtivo diante das diferentes situações sociais. Dessa forma, a escola desempenha um importante papel na construção de uma sociedade mais justa e igualitária. Nessa perspectiva, Silva e Dallanol (2008), apontam que a escola e a educação têm como fundamento contribuir para a construção de conhecimentos básicos e de valores essenciais para a prática cidadã dos alunos.

E para que isso aconteça no ambiente escolar, é necessário que os cursos de licenciaturas formem docentes que atuem com esse viés. No entanto, o que se tem observado, assim como aponta Libâneo (2015), é que a organização do currículo dos cursos de formação inicial de professores apresenta forte dicotomização entre saberes específicos e saberes pedagógicos, formando o professor especialista. Com isso, o docente não conseguirá atuar como mediador entre o conhecimento e o aluno e, dessa maneira, o aluno pode apresentar dificuldades em se apropriar do que é ensinado e, consequentemente, em entender o mundo que o cerca.

E diante das constantes transformações que a sociedade está sujeita, entendemos, assim como Rosa et al. (2012), que é preciso que haja uma integração dos cursos formadores de professores com a realidade social que se encontram, só assim, esses cursos serão capazes de formar docentes éticos, críticos e reflexivos, aptos a auxiliarem na formação de seus educandos. Pensando nisso, a disciplina de Metodologia do Ensino de Ciências do curso de licenciatura em Ciências Biológicas da Universidade Federal de Lavras-MG propôs aos discentes a construção de metodologias de ensino de ciências para alunos do Ensino Fundamental, destacando a importância da atividade proposta na formação de professores.

Dessa forma, apresentaremos uma experiência realizada no âmbito da disciplina para o ensino de astronomia. E assim como aponta Lima (2006), o desenvolvimento do pensamento humano sempre esteve atrelado à astronomia, possibilitando até o avanço tecnológico. E Soler (2012) continua dizendo que seu estudo tem como característica estimular a atenção, interesse e curiosidade de diferentes públicos, principalmente professores e alunos. $\mathrm{O}$ autor ainda diz que o estudo da astronomia permite maior compreensão dos fenômenos que acontecem na natureza e, por isso, possibilita aos estudantes uma ampliação da visão de mundo. Sendo assim, é imprescindível que o seu ensino seja trabalhado dentro de sala de aula com sujeitos, ainda, em formação. E dentro do assunto de astronomia, foi trabalhado o tema "Estações do ano", que segundo Silva (2014) permite a compreensão dos fenômenos cíclicos naturais do Planeta Terra. A autora ainda diz que a apropriação desses conceitos permite a construção de uma nova relação com a Terra e uma ampliação da visão do Universo.

E como estratégia pedagógica para o ensino de Estações do ano, utilizamos a mitologia grega, pois, segundo Ferreira e Nascimento Junior (2014) os mitos podem caracterizar-se como recursos pedagógicos eficientes, já que trazem elementos que nos permitem compreender parte da história e da existência da humanidade. Ainda, a estrutura mitológica tem uma grande importância antropológica, já que demonstra a cultura e o pensamento de um povo 
(MURARI e CAPORALINI, 2007, p.16). Nessa perspectiva, a utilização dos mitos em sala de aula permite aos professores trabalharem a questão do multiculturalismo, buscando entender com os alunos as diversas culturas existentes a fim de entender como essas culturas influenciaram a sociedade como vemos hoje e, também, busca superar o preconceito cultural.

Diante dessas considerações, o presente trabalho tem como objetivo, além de apresentar a experiência desenvolvida no âmbito da disciplina, discutir seus resultados a fim de entender como a utilização da mitologia auxiliou na construção de conhecimentos e como a própria disciplina contribui para a formação inicial de professores de ciências.

\section{DESENVOLVIMENTO DO TRABALHO Proposta da aula}

A proposta de aula aqui apresentada é uma construção, a partir da disciplina de Metodologia do Ensino de Ciências, que é ofertada no terceiro período do curso de licenciatura em Ciências Biológicas da Universidade Federal de Lavras-MG (UFLA). E tem o objetivo de auxiliar na identidade docente dos licenciandos, na construção de um olhar crítico acerca do sistema educacional que está colocado, além de minimizar o distanciamento entre a formação pedagógica e formação específica existente no curso.

A proposta de aula foi baseada em um dos eixos temáticos dos Parâmetros Curriculares Nacionais (BRASIL, 1998), Terra e Universo. Orientada pelo Currículo Básico Comum de Minas Gerais (MINAS GERAIS, 2007). O tema da aula foi "estações do ano". A metodologia construída foi fundamentada na relação professor-aluno, pois quando essa relação se dá de forma harmoniosa facilita o processo de ensino e aprendizagem. E assim como apontam Smolka e Góes (1995), a mediação é representada pela relação "sujeito-sujeito-objeto", onde o sujeito vai conseguir estabelecer relações com o objeto do conhecimento através de outro sujeito.

Para a construção dos conhecimentos com os estudantes utilizamos um modelo do Planeta Terra feito com bola de isopor, com isso, buscava-se uma aproximação entre o tema da aula e alunos facilitando a compreensão dos conceitos ensinados. Ainda, usamos, também, a mitologia grega: Hades e Perséfone, o Amor no Reino dos Mortos, com isso, foi trabalhada a questão da pluralidade cultural, um dos temas transversais sugeridos pelos Parâmetros Curriculares Nacionais. Os temas transversais expressam conceitos e valores fundamentais à democracia e à cidadania e correspondem a questões importantes e urgentes que necessitam ser discutidas junto à sociedade brasileira (BOVO, 2005).

Após o tema da aula e a estratégia pedagógica serem escolhidos, o projeto de aula foi apresentado aos bolsistas do Programa Institucional de Bolsas de Iniciação à Docência (PIBID) de Biologia da UFLA, no qual apontaram os pontos positivos e os pontos que poderiam ser melhorados na metodologia, a fim de potencializar o processo de ensino e aprendizagem. 


\section{Descrição da aula}

A aula foi ministrada aos licenciandos que estavam matriculados na disciplina e teve duração de 30 minutos e foi dividida em três momentos. O primeiro momento foi iniciado através da mitologia grega: Hades e Perséfone, o Amor no Reino do Mortos, que, resumidamente, conta a história de quando Hades se apaixona por Perséfone e ao ter seu desejo de casar-se com ela negado, por conta de Deméter a Deusa da agricultura, sua mãe, resolve capturar sua amada, onde tornara-se a Deusa de Érebo. E uma vez que adentrasse o reino de Hades não poderia mais sair dele, Deméter ficou desolada e, então, abandonou o campo e as plantações e, com isso, a primavera deu lugar ao inverno e à fome.

Diante do que estava acontecendo Zeus pede a Hades que devolva Perséfone à mãe para que as plantações voltem a ser cuidadas e os mortais não morram de fome e nem se voltem contra os Deus. Mesmo contrariado, Hades faz o que Zeus pede, no entanto, oferece à Perséfone uma romã, que come, no entanto, quem come qualquer fruta no Érebo, a ele deve retornar. Então, Perséfone passa parte do ano reinando com Hades, que faz sua mãe ficar profundamente triste e, consequentemente, as árvores perdem as folhas e as flores e o inverno chega. E a outra parte do ano passa com sua mãe que ao receber a filha, alegra-se novamente, com isso, com o cuidado das plantações, as folhas das árvores voltam e as flores tomam conta do campo, trazendo novamente a primavera ao mundo. A utilização da mitologia grega teve o intuito de trabalhar a questão da pluralidade cultural, um dos temas transversais propostos pelos Parâmetros Curriculares Nacionais.

No momento seguinte, foi pedido aos alunos para formarem um círculo para dar início a uma dinâmica, então, foi apresentado a eles um globo terrestre feito com bola de isopor, em seguida foram feitas as seguintes problematizações: o que é isso? O que representa? E qual sua posição em relação ao sol? Com as respostas dos alunos foi trabalhado as questões de inclinação da Terra em relação ao sol e seu movimento de rotação e translação.

Então, novas problematizações contextualizadas foram levantadas, entre elas: como está a temperatura esses dias? Isso ocorre durante todo o ano? Por que isso acontece? E por que existe essa variação de temperatura? Com as respostas dos alunos, foram sendo construídos os conceitos de estações, o porquê da diferença de clima nos hemisférios na mesma época do ano, além de diferenciar equinócio de solstício. Durante este processo, para relacionar a mitologia utilizada com o conceito científico, foi pedido a alguns alunos que escolhessem algum local no globo. Após escolherem, foram levantadas as seguintes questões: Considerando a posição em que o globo se encontra em relação ao sol, neste local, Perséfone estaria com sua mãe Deméter ou com Hades? Por quê? Que estação seria? 


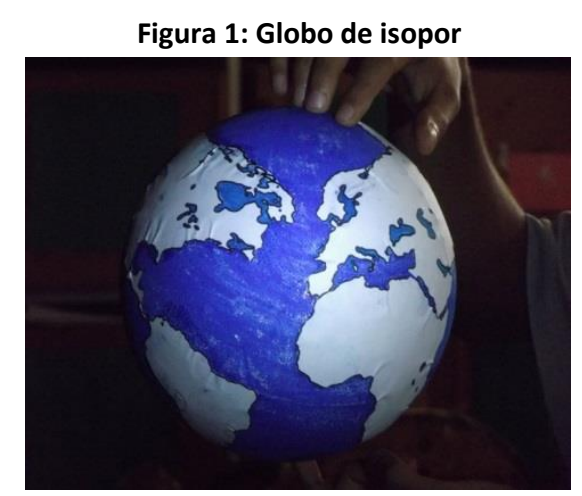

Fotografado por Antonio Fernandes Nascimento Junior, 2015.

No terceiro momento, os alunos foram divididos em quatro grupos e foi proposto a cada grupo para criarem um mito acerca de cada estação do ano partindo do que foi ensinado durante a aula. Foi sorteada uma estação para cada grupo. Com esta atividade, foi possível despertar a criatividade dos alunos ao incentivar a criação de uma história e, ainda, avaliar o processo de ensino-aprendizagem, verificando se os objetivos da aula foram alcançados.

Após o término da aula, onde todos os grupos apresentaram os mitos criados, foi pedido aos discentes da disciplina que escrevessem uma avaliação da prática realizada, onde deveriam apontar os pontos positivos e os pontos negativos da metodologia desenvolvida. Estas avaliações foram utilizadas para a análise do presente trabalho.

\section{METODOLOGIA}

Para verificar a contribuição da aula ministrada para a contribuição da construção dos conhecimentos com os alunos foi utilizada a pesquisa qualitativa, pois assim como aponta Flick (2008), é uma pesquisa que tem como aspectos essenciais a apropriação métodos e teorias, perspectivas dos participantes e sua diversidade, reflexividade do pesquisador e sua pesquisa e variedade de abordagens e métodos na pesquisa qualitativa. E dentro da pesquisa qualitativa, foi utilizada a análise de conteúdo, que segundo Silva et al. (2005) é uma ferramenta empregada para entender a construção de significados que os atores sociais expressam em seus discursos.

Ainda, a análise por categorias, derivada da análise de discurso, também foi utilizada para a compreensão dos fenômenos estudados. E segundo Bardin (1977), categorizar é fazer um agrupamento de ideias que possuem elementos em comum. A autora ainda diz que o critério para a elaboração das categorias pode ser semântico, sintático, léxico e expressivo. 


\section{RESULTADOS E DISCUSSÃO}

Segue abaixo as avaliações utilizadas para análise do presente trabalho. Para manter o sigilo dos participantes, cada um foi identificado com a letra $\mathrm{X}$ e um número para diferenciá-los.

X1 - "Foi uma aula que me despertou a imaginação fazendo com que a matéria tornasse visível, uma criatividade muito grande, como as aulas anteriores ocorreu uma interação coletiva com a dinâmica. Soube passar o conteúdo sem ser uma aula cansativa, uma aula gostosa de assistir".

X2 - "A aula conseguiu abordar o conteúdo completamente, a "professora" explicou com muita didática e conseguiu envolver os alunos em questionamentos e discussões. O uso da mitologia conseguiu ser relacionado durante as explicações. O uso de vários questionamentos conseguiu inteirar os alunos do assunto e ao mesmo tempo revisálo. A aula cumpriu seu objetivo".

X3 - "A Letícia apesar de estar sozinha se comportou muito bem, iniciando com uma historinha para envolver os alunos. Posteriormente vindo a parte "teórica", mas não com metodologia massacrante".

X4 - "Utilização de uma história como tema transversal ligada com outra metodologia não expositiva, que deixou o conteúdo de forma interessante e clara além de ter uma interação entre todos os alunos com perguntas e demonstrações.

*Utilização de um método objetivo e eficaz para avaliação tendo em vista saber todo o conteúdo que foi passado durante a aula.

*A interação e combinação de todas as metodologias usadas".

X5 - "Trabalho muito bem elaborado, criativo e educativo. A apresentadora conseguiu transmitir o conhecimento de forma didática e entrar dentro dos padrões de apresentação".

X6 - "O início da aula começando a ser contando com uma história desperta interesse aos alunos. Foi uma metodologia participativa, onde no final da aula todos montavam sua própria história sobre as estações, e todos participaram. A aula quanto mais se introduz os alunos no assunto, melhor o rendimento".

X7 - "A aula apresentada por Letícia, foi uma aula bem participativa, com a ajuda dos colegas de sala ela nos mostrou todas as estações, explicando o porquê da ocorrência delas e como acontece, além de explicar tudo isso através de uma mitologia grega. No final houve a separação da turma em grupos, onde todos os alunos realizaram uma atividade, com isso tomando o rumo da aula fugindo do esquema expositivo".

X8 - "A aula conseguiu cumprir seu objetivo de não ser expositiva, bastante interativa e didática. $\mathrm{O}$ método avaliativo foi bem elaborado trazendo a ideia de mitologia como algo explicativo retomando ideias do passado de como os povos explicavam os acontecimentos antigos". 
X9 - "O objetivo da aula foi com que aprendêssemos sobre as estações do ano, e o objetivo foi concluído. O tema foi abordado de forma transversal na hora da história já que mostrava um pouco da cultura grega. A parte mais interessante foi a dinâmica onde era possível entender o motivo de existir as quatro estações, foi bem didático e simples. Apenas senti que faltou explicar o porquê precisamos aprender sobre as estações do ano, mas de resto achei uma aula super proveitosa, produtiva e didática". X10 - "A aula sobre as estações climáticas onde foi ensinado a relação entre a translação da Terra e sua inclinação foi de grande entendimento. A aprendizagem, no entanto, pode ser mais exemplificada caso seja dada em uma turma do ensino fundamental, devido a alguns termos científicos usados".

X11 - "A metodologia utilizada supriu as necessidades compreendidas no PCN, trazendo como eixo transversal a cultura (e como sugestão, se aplicada uma próxima vez, com mais tempo, pudesse abordar também o quesito econômico que o assunto implica). A professora soube envolver os alunos em todos os momentos da aula".

X12 - "A introdução da aula começou com a história da mitologia grega, relacionada com as estações do ano. Letícia soube abordar o tema de modo que todos os alunos participassem, com perguntas levando em consideração ao que os alunos de alguma forma já haviam escutado em algum momento. Usou um método avaliativo de forma dinâmica para que os alunos se sentissem a vontade, mostrando sua criatividade e que conseguiram entender a aula de um jeito tranquilo".

X13 - "Achei a aula interessante principalmente porque a Letícia conseguiu escolher bem a história da mitologia que relaciona com as estações do ano de uma forma muito didática que prende a atenção. A dinâmica foi boa, e a Letícia estava preparada para responder as dúvidas que surgiram se mostrando bem confiante mesmo dando aula sozinha. O único problema que vi foi na hora da dinâmica que ficou um pouco difícil de visualizar (talvez porque ela apresentou sozinha e talvez não ensaiou com outra pessoa), numa próxima aula talvez seria bom colocar um eixo na bola que representava a Terra para facilitar a visualização da inclinação".

X14 - "Achei a metodologia condizente com o objetivo da aula. A professora se apropriou do conteúdo e mesmo com as dúvidas dos estudantes ela conseguiu explicar de formas diferentes e mais aperfeiçoadas posteriormente.

A história foi bem contada!

O método avaliativo foi criativo e divertido.

Existe a possibilidade de se colocar um palito furando os polos do globo terrestre para a visualização da inclinação do ângulo da Terra ser mais facilitada".

X15 - "*A metodologia foi condizente com o tema, alguns momentos um pouco confusos, mas no final houve entendimento do conteúdo abordado.

* Muitas perguntas para os alunos havendo participação na aula.

* O conteúdo foi condizente com o que é pedido no PCN.

*A mitologia bem clara para "explicar" a parte científica, trazendo um aspecto também cultural". 
X16 - "A história contada como metodologia para ensinar as estações do ano mostrou com clareza aos alunos como funcionava as estações do ano e houve uma dinâmica que demonstrou fisicamente as mudanças das estações no nosso planeta; esclareceu aos alunos os conceitos de inclinação da Terra e movimento de translação. Ao final, a atividade proposta foi bem interessante pois despertou a criatividade dos alunos".

X17 - "Apenas com uma história de mitologia é possível entender qual é o tema da aula. História essa, com utilização de imagens que pareceu servir para os alunos imaginarem, de fato, os acontecimentos.

Com a dinâmica utilizada, todos puderam participar do andamento da aula, dizendo o que sabiam e o que tinham entendido".

X18 - "A aula apresentou um desenvolvimento bem definido e organizado. Em um primeiro momento, pareceu que a história de Perséfone e Hades estava sendo demasiadamente longa para cumprir com o objetivo da aula. No entanto, no segundo momento da aula, a lenda fornece uma ideia intuitiva do que ocorre quando as estações mudam. Deixando claro que era a forma como os antigos gregos explicavam como ocorria os solstícios e equinócios, ocorrendo de maneira oposta em cada hemisfério devido a inclinação da Terra e o movimento de translação. Um ponto bem interessante e que fez/faz muita diferença na interação entre alunos e professores na sala de aula, foram os constantes questionamentos da Professora. De maneira tal que todos se sentiram à vontade para participar da aula, encontrando as respostas para as questões que foram levantadas. A metodologia de avaliação foi uma escolha bem interessante, pois permitiu aos alunos que criassem sua própria história explicando algum fenômeno natural, o que foi de encontro ao principal objetivo da aula.

A parir da análise das avaliações foram elaboradas quatro categorias. E como já mencionado aqui no trabalho, as falas foram agrupadas por conterem elementos em comum. Abaixo trazemos um quadro apresentando as categorias, a descrição, a frequência e a ocorrência de cada uma delas. 
Quadro 1: Categorias, descrição e frequência.

\begin{tabular}{|c|c|c|}
\hline Categorias & Descrição & Frequência \\
\hline $\begin{array}{l}\text { Mitologia como recurso } \\
\text { pedagógico }\end{array}$ & $\begin{array}{l}\text { Esta categoria remete às falas que destacaram a utilização da } \\
\text { mitologia grega relevante na construção de conhecimentos. }\end{array}$ & 12 \\
\hline $\begin{array}{l}\text { Metodologias Alternativas de } \\
\text { ensino }\end{array}$ & $\begin{array}{l}\text { Destacam-se aqui as falas que fazem referência à importância } \\
\text { de uma aula participativa para consolidação e apropriação dos } \\
\text { conteúdos ensinados. }\end{array}$ & 10 \\
\hline Problematização no ensino & $\begin{array}{l}\mathrm{Na} \text { categoria "Problematização" reúne as falas que } \\
\text { ressaltaram a relevância dessa estratégia pedagógica no } \\
\text { processo de ensino e aprendizagem. }\end{array}$ & 5 \\
\hline Dinâmica de grupo & $\begin{array}{l}\text { Concentram-se aqui as falas que destacam a dinâmica de } \\
\text { grupo como importante no processo de interação entre } \\
\text { alunos e professor. }\end{array}$ & 5 \\
\hline
\end{tabular}

Ao analisarmos a primeira categoria, percebemos que 12 licenciandos apontaram em seus relatos escritos a importância do diálogo entre a mitologia e a construção do conceito de Estações do ano, sendo assim, podemos inferir que essa relação pode ser trabalhada de forma mais frequente dentro de sala de aula, a fim de maximizar o processo de ensino e aprendizagem. A utilização da mitologia fornece elementos aos professores para abordarem como a questão da origem do homem, do mundo e da vida era explicada e passada entre a diversas gerações. Nesse sentido, Leal e Gouvêa (2000) dizem que o mito é transmitido sob o olhar das culturas, das religiões, do imaginário, das relações de poder, do gênero etc. Dessa forma, é possível discutir como as relações sociais influenciam a maneira como o mundo era visto, podendo ainda, comparar como essas relações interferem no modo que entendemos o mundo atualmente.

Nessa perspectiva, o uso de mitologia em sala de aula, quando trabalhado de maneira que traga o contexto histórico para entender o processo de construção e acúmulo de conhecimentos pela humanidade, permite aos estudantes a criação de um olhar crítico acerca desse processo de apropriação desses conhecimentos, já que seriam trabalhados a fim de entender seus processos de construção e não, simplesmente, seus resultados, assim como acontece nas escolas brasileiras que se utilizam da pedagogia tradicional para o ensino de ciências. Essa pedagogia apresenta os conceitos aos alunos de forma fragmentada, impossibilitando que se enxergue o mundo de forma holística.

Ainda, Murari e Caporalini (2007) apontam que a utilização da mitologia em sala de aula, além de permitir que os alunos compreendam o mundo em sua totalidade, possibilita que professor e aluno desempenhem um bom papel no âmbito escolar, pois o professor vai conseguir construir os conceitos a serem ensinados e os alunos irão desenvolver sua capacidade de raciocínio. Os autores ainda dizem que até a relação professor-aluno é melhorada. Diante disso, é notável a relevância dos mitos na apropriação do que é ensinado em sala de aula pelos estudantes, diminuindo as dificuldades encontradas pelos professores no auxílio da formação dos educandos numa perspectiva crítica e reflexiva.

$\mathrm{Na}$ segunda categoria observamos que 10 alunos destacaram a utilização de uma metodologia alternativa de ensino que fuja do modelo tradicional, presente de forma majoritária nas 
escolas brasileiras, como importante estratégia para consolidação e apropriação dos conteúdos ensinados. Diante desses apontamentos, podemos inferir que o modelo tradicional de ensino deve ser superado a fim de potencializar o processo de ensino e aprendizagem, já que este modelo de educação hegemônico se concentra na capacidade de memorização dos estudantes e, assim como afirma Leão (1999), partindo do pressuposto que todos os estudantes são iguais.

Sendo assim, para que se supere esse modelo, é dever dos cursos de formação de professores criar meios para que os futuros docentes se aprofundem nas diferentes teorias pedagógicas para que reconheçam os problemas encontrados nas tendências pedagógicas liberais, que segundo Libâneo (2005), são manifestações da ordem social vigente que é baseada na doutrina liberal. $\mathrm{O}$ autor ainda aponta que essa doutrina criou uma organização na sociedade baseada nos meios de produção privados que acentuam as desigualdades sociais, dividindo a sociedade em classes.

Libâneo (2005) também destaca que nas últimas décadas a educação brasileira tem sido caracterizada pelas tendências pedagógicas liberais. E o que se tem observado, devido à uma má formação teórica durante o período acadêmico, é que boa parte dos docentes limitam sua prática a suposições pedagógicas, sem saber que por detrás disso existem pressupostos pedagógicos, daí a importância dos cursos formadores de professores no auxílio à construção de docentes com formação teórica sólida. Assim os futuros professores poderão contribuir para a formação de seus educandos numa perspectiva crítica, onde entendam a realidade na qual estão inseridos e atuem de forma ativa nas decisões da sociedade.

A terceira categoria nos aponta que o uso de problematizações durante a aula aguça a curiosidade dos alunos deixando-os mais atentos, sendo assim, torna-se um elemento essencial ao processo pedagógico, pois favorece o fenômeno de ensino e aprendizagem, além de atribuir maior sentido aos conteúdos. E segundo Ricardo (2010), a problematização está contida na formulação de situações-problema que irão compor o processo de ensino durante a aula. $\mathrm{O}$ autor ainda ressalta que as situações-problema não irão se constituir sozinhas, pois não se trata de exemplificar o conteúdo o ensinado e diluir em generalidades, é preciso desenvolver um ambiente de aprendizagem que cria possibilidade para a apropriação dos conceitos trabalhos nesse processo.

A problematização também está contida nas relações dentro de sala de aula, pois são situações do cotidiano dos alunos que estão sendo discutidas, dessa maneira, a situaçãoproblema colocada pelo professor deve permitir o diálogo com os estudantes, onde as respostas apresentadas não sejam apenas sim/não, contra/a favor, conheço/não conheço, sei/não sei (RICARDO, 2010). A fala do autor nos permite inferir que a relação estabelecida entre professor e alunos interfere, diretamente, na eficiência da utilização da problematização durante a aula e, por conseguinte, no processo de ensino e aprendizagem. Sendo assim, é imprescindível que professor e alunos estabeleçam uma boa relação.

Ainda, ao problematizar um tema, vale destacar, assim como Ricardo (2010), que a situaçãoproblema deve encaminhar o aluno à formulação de novos problemas, não ficando limitado, somente, ao proposto pelo professor. E para além da sala de aula, Halmenschlager (2010) 
indica que ao analisar o contexto do ensino de ciências, a problematização pode se apresentar como uma alternativa metodológica podendo contribuir de forma significativa na construção do currículo de ciências.

$\mathrm{Na}$ quarta categoria, cinco estudantes destacaram a importância da dinâmica de grupo realizada como estratégia que aproximou professores e alunos, facilitando o processo pedagógico em sala de aula. Nessa perspectiva, Libâneo (2012) destaca que essas atividades permitem ao professor entender que o ato docente não está em trabalhar com sujeitos isolados, mas sim, saber lidar com a coletividade do grupo. $\mathrm{O}$ autor ainda afirma que isso faz $\mathrm{o}$ professor ganhar a confiança dos alunos.

Esse tipo de estratégia, que envolva atividades coletivas, contribui para a formação de sujeitos democráticos que atuam de forma ativa dentro de sua cultura (SOUZA, 2013). Dessa forma, é possível inferir que a utilização de dinâmicas de grupo em sala de aula é extremamente necessária para a construção de uma sociedade mais justa e igualitária. No entanto, assim como Souza (2013) ressalta, é importante estar atento ao tempo e às possibilidades de adicioná-las à prática educativa, uma vez que essa atividade tem o objetivo de propor momentos educativos que viabilizem ao grupo vivenciar momentos inovadores. A autora continua dizendo que para que isso aconteça é preciso tem em mente que o aluno é sujeito ativo do processo de ensino.

Diante disso, é perceptível que, enquanto ferramenta pedagógica, a dinâmica de grupo potencializa o processo de ensino e aprendizagem, pois pode contribuir, de forma significativa, com o desenvolvimento da capacidade dos alunos de construir e se apropriar de conceitos. No entanto, assim como afirma Souza (2013), entendemos que a dinâmica de grupo por si só não consegue dar conta o desenvolvimento em sua totalidade do processo pedagógico. Nesse sentido, Priotto (2008) recomenda que antes de se aplicar a dinâmica de grupo, o professor conheça bem a turma, assim, imprevistos são minimizados e processo de ensino potencializado.

\section{CONSIDERAÇÕES FINAIS}

A disciplina se mostrou como importante espaço de formação docente, pois, além de permitir que os licenciandos ampliem sua visão acerca do contexto em que as licenciaturas se inserem, possibilita a construção de materiais pedagógicos para o ensino de ciências que fogem do modelo tradicional de ensino. Ainda, é nesse período do curso de licenciatura em Ciências Biológicas da UFLA que os discentes começam a mobilizar e articular os conhecimentos específicos e os saberes pedagógicos, minimizando a dissociação entre esses elementos que são fundamentais para a profissão docente.

A disciplina também destaca os problemas enfrentados na apropriação dos conteúdos quando se utiliza de metodologias expositivas no ensino. E a partir da análise e discussão do presente trabalho, nos permite inferir que a utilização da mitologia grega se mostra como uma estratégia pedagógica eficiente para o ensino de ciência, em específico nesse texto, a construção do conceito de estações do ano, facilitando o processo de construção de 
conhecimentos, além de possibilitar que seja trabalhado a pluralidade cultural com os alunos, formando-os numa perspectiva crítica.

Ainda, é necessário destacar a importância dos bolsistas do Programa Institucional de Bolsas de Iniciação à Docência (PIBID) de Biologia da UFLA na construção da aula apresentada. Esse diálogo entre o PIBID e a disciplina ocorre todo semestre e tem se mostrado eficiente no processo de formação de professores, sendo assim, esse fica evidente a importância da permanência dessa prática formativa.

\section{AGRADECIMENTOS: CAPES.}

\section{REFERÊNCIAS BIBLIOGRÁFICAS}

BARDIN, Laurence. Análise de conteúdo. Lisboa, Edições 70, 1977.

BOVO, Marco Clair. Interdisciplinaridade e transversalidade como dimensões da ação pedagógica. Revista Urutágua, Maringá, n. 7, p. 1-11. Quadrimestral no 07, 2005.

BRASIL. Parâmetros Curriculares Nacionais: $3^{\circ}$ e $4^{\circ}$ ciclos: apresentação dos temas tranversais. Secretaria de Educação Fundamental. Brasília, DF: MEC/SEF, 1998.

FERREIRA, Wellington Donizet; NASCIMENTO JUNIOR, Antonio Fernandes. A mitologia grega como estratégia para o ensino de zoologia: articulando a biologia com a língua portuguesa e suas literaturas. In: XXIII Congresso de PósGraduação da UFLA, 2014, Lavras. Anais do XXIII Congresso de Pós-Graduação da UFLA, 2014.

FLICK, Uwe. Introdução à pesquisa qualitativa-3. Artmed editora, 2008.

HALMENSCHLAGER, Karine Raquiel. Problematização no ensino de Ciências: uma Análise da Situação de Estudo. Universidade Federal de Santa Catarina/Programa de Pós-Graduação em Educação Científica e Tecnológica. 2011.

LEAL, Maria Cristina; GOUVÊA, Guaracira. Narrativa, mito, ciência e tecnologia: o ensino de Ciências na Escola e no Museu. Ensaio - Pesquisa em Educação em Ciências. Vol. 92. № 1. 2002.

LEÃO, Denise M. Maciel. Paradigmas contemporâneos de educação: Escola tradicional e escola construtivista. Cadernos de Pesquisa, no 107, p. 187-206, julho/1999.

LIBÂNEO, José Carlos. Pedagogia e pedagogos, para quê? São Paulo: Cortez, 2005

LIBÂNEO, José Carlos. Democratização da escola pública: a pedagogia crítico-social dos conteúdos. 27. ed. São Paulo: Edições Loyola, 2012. V.1. 160p

LIBÂNEO, José Carlos. Formação de Professores e Didática para Desenvolvimento Humano. Educação \& Realidade, Porto Alegre, v. 40, n. 2, p. 629-650, abr./jun. 2015.

LIMA, José E. Machado de. A visão do professor de ciências sobre as estações do ano. 2006. 110f. Dissertação (Mestrado em Ensino de Ciências e Educação Matemática) - Universidade Estadual de Londrina, Londrina, 2006.

MINAS GERAIS (Estado). Secretaria de Estado de Educação de Minas Gerais. Currículo Básico Comum - Proposta Curricular Ciências e Biologia. - Belo Horizonte: SEE, Minas Gerias, 2007. 
Murari, Juliana Cristhina Faizano; CAPORALINI, José Beluci. A Importância da Mitologia para o Ensino de Filosofia nas Séries Iniciais. I Encontro de Pesquisa em Educação, IV Jornada de Prática de Ensino, XIII Semana de Pedagogia da UEM: "Infância e Práticas Educativas". Arq Mudi. 2007.

PRIOTTO, Elis Palma. Dinâmicas de grupo para adolescentes. 2. ed. Petrópolis: Vozes, 2008.

RICARDO, Elio Carlos. Problematização e contextualização no ensino de física. In: Carvalho, A. M. P. (org.). Ensino de Física. São Paulo: Cengage Learning, 2010.

ROSA, Rafaela Mahiane; REIS NETO, João Augusto; OSIO, Fernando J. Godoy; ANDRADE, Samara M. Moreira de; BELTRAME, Yara. ; FARIA, Lucas Del Bianco; NASCIMENTO JUNIOR, Antonio Fernandes. Elaboração de um jogo didático a partir de uma proposta da disciplina de Biologia de Populações do curso de Biologia da Universidade Federal de Lavras. Revista de Ensino de Biologia da Associação Brasileira de Ensino de Biologia (SBEnBio), v. 5, p. 1-7, 2012.

SILVA, Daniella M. Cunha. Saberes ambientais e estações do ano. 2014. 185f. Dissertação (Mestrado em Ciências Naturais e Educação Matemática) - Universidade Federal do Rio Grande do Norte, Natal, 2014.

SILVA, Cristiane Rocha; GOBBI, Beatris Christo; SIMÃO, Ana Adalgisa. O uso da análise de conteúdo como uma ferramenta para a pesquisa qualitativa: Descrição e aplicação do método. Organizações Rurais Agroindustriais, 7(1), 70-81, 2005.

SILVA, Francielli Pirolli; DALLANOL, Rodrigo Assufi. A Educação como Processo da Formação Social do Indivíduo. In: $1^{\circ}$ Simpósio Nacional de Educação, 1., 2008, Cascavel - PR. XX Semana da Pedagogia...UNIOESTE: [s.n.], 2008.

SMOLKA, Ana Luiza Bustamante; GÓES, Maria Cecília. (orgs.) (1995) A linguagem e o outro no espaço escolar: Vygotsky e a construção do conhecimento. São Paulo: Editora Papirus. 1995.

SOLER, Daniel Rutkowski. Astronomia no currículo do estado de São Paulo e nos PCN: um olhar para o tema observação no céu. 2012. 200f. Dissertação - Instituto de Física, Instituto de Química e Instituto de Biociências, Universidade de São Paulo, São Paulo. 2012.

SOUZA, Vanilsa Pereira de. Dinâmicas de grupo como estratégia para a aprendizagem significativa de polímeros sintéticos. 2013. 118f. Dissertação (Mestrado Profissional em Ensino Ciências Exatas) - Centro Universitário Univates, Lajeado, 2013. 